\title{
COMPOSIÇÃO QUÍMICA E ANÁLISE SENSORIAL DO IOGURTE GREGO COMERCIALIZADO NO SUL DO ESTADO DE MINAS GERAIS
}

\section{Chemical composition and sensory analysis of Greek yogurt traded in the South of the state of Minas Gerais}

\author{
Alex Uzêda de Magalhães ${ }^{1}$, Ana Clara Gonçalves Della Torre ${ }^{*^{*}}$
}

\begin{abstract}
RESUMO
O ramo de laticínios tem se mostrado em constante evolução. Este trabalho objetivou analisar físico química e sensorialmente uma tendência promissora deste setor: o iogurte grego. Encontramos no mercado brasileiro variedade de marcas, onde se observa uma diferença nos atributos sensoriais e na composição química das mesmas, devido à falta de um padrão de qualidade e identidade específico deste produto. Para avaliar este cenário, foram coletadas amostras de cinco marcas (A, B, C, D e E) amplamente encontradas no Sul do Estado de Minas Gerais, em três lotes diferentes. Observou-se uma discrepância na composição química a qual foi refletida na análise sensorial. A marca $B$ apresentou maior valor para acidez e menores valores para sólidos totais, gordura, proteína e L*, sendo, consequentemente, a menos aceita para os atributos aparência e sabor. Já a marca A, apresentou maior valor para proteína e maior aceitação no aspecto consistência. A partir dos resultados obtidos neste trabalho, foi determinado um perfil de iogurte grego integral natural que melhor se adequa ao consumidor, com valores próximos à média dos resultados encontrados nas marcas comerciais para, sólidos totais, gordura e acidez; e um maior teor proteico.

Palavras-chave: leite fermentado; labneh; qualidade; padronização.
\end{abstract}

\begin{abstract}
The dairy sector in the food industry has shown a permanent evolution. This study aimed to analyze a promising trend in this sector: the Greek yogurt. It can be

1 Instituto Federal do Sul de Minas Gerais, Campus Machado, Rod. Machado - Paraguaçu s/n., Santo Antonio, 37750-000, Machado, MG, Brasil. E-mail: anaclaratorre95@gmail.com.

* Autor para correspondência.
\end{abstract}

Recebido / Received: 11/09/2017

Aprovado / Approved: 15/05/2018 
found in the Brazilian market a range of brands and, due to lack of specific legislation for this product, there may be a difference in sensory attributes and chemical composition. To evaluate this scenario, five brands samples were collected in the southern state of Minas Gerais, in three different lots. A discrepancy in the chemical composition was observed, which was reflected in the sensory analysis. The brand B presented greater value for acidity and lower values for total solids, fat, protein and $\mathrm{L}^{*}$, and hence it wasless accepted for the attributes of appearance and taste. The sample A showed the highest value for protein and hence greater acceptance in the consistency point. Based on the results obtained in this work, a profile of natural Greek yoghurt that best suits the consumer was determined, with values close to the average of the results found in the trade marks for total solids, fat and acidity; and a higher protein content.

Keywords: fermented milk; labneh; quality; standardization.

\section{INTRODUÇ̃̃O}

O iogurte é definido como o produto obtido por coagulação e diminuição do $\mathrm{pH}$ do leite, ou leite reconstituído, adicionado ou não de outras substâncias alimentícias, por fermentação láctica mediante ação de microrganismos específicos. Estes microrganismos específicos devem ser viáveis, ativos e abundantes no produto final durante seu prazo de validade. A fermentação láctica se realiza somente com cultivos simbiótico de Streptococcus salivarius subsp. thermophilus e Lactobacillus delbrueckii subsp. bulgaricus, aos quais se podem acompanhar, de forma complementar, outras bactérias lácticas que, por sua atividade, contribuem para a determinação das características do produto final (BRASIL, 2007).

A evolução do mercado de iogurte foi ditada pelas forças do comércio e da demanda do consumidor. Diferentes tipos ou variedades de iogurte entraram no mercado em resposta a preferência do consumidor, mudando estilos de vida e ajustes na dieta. Uma exemplificação desse cenário é o iogurte grego, que possui várias formulações. Estas formulações variam também com a sazonalidade, sendo que, na Europa, possui alto teor de gordura, baixa dose de proteína e pequena participa- ção no mercado. Nos Estados Unidos, este produto possui menos gordura, mais proteína e domínio de $23 \%$ das vendas sobre os outros laticínios. As diferenças ocorrem pela ausência de definição legal do conceito iogurte grego. O iogurte grego, propriamente dito, feito e consumido em larga escala na Grécia, geralmente é produzido de forma caseira. Devido a isso, as diferenças nas formulações e processamentos iniciaram-se na origem do alimento (FERREIRA, 2014).

Mais cremoso e com maior concentração proteica e lipídica, quando comparado com o iogurte integral natural, o iogurte grego foi introduzido no mercado brasileiro como um alimento de nova segmentação de mercado no ramo de laticínios, que se encontrava em uma monotonia no setor de iogurte (LANGSDORFF, 2012).

Como principais características, ele é um iogurte drenado, e, portanto, concentrado em proteínas e gorduras, mais firme e viscoso que os demais produtos similares, sendo viável o seu consumo de colher. No Brasil, como a regulação do iogurte grego ainda não foi definida, há marcas que adicionam outros ingredientes além de leite e fermento lácteo, como espessantes e creme de leite, com o objetivo de garantir a consistência característica do produto. A firmeza do iogurte é um 
atributo importante na aceitação do produto pelo consumidor. No iogurte grego, a textura, principalmente no parâmetro de firmeza, é uma propriedade que tem papel fundamental na qualidade do produto final (COSTA et al., 2014).

Por ser um produto relativamente novo no mercado alimentício brasileiro, ainda não foi destinado ao mesmo a atenção necessária das autoridades para a padronização de um Regulamento Técnico de Identidade e Qualidade específico deste produto, existindo somente para o iogurte em geral. Por este motivo, os consumidores têm a sua disposição uma variedade de marcas de iogurte grego, sendo possível que as mesmas possuam características significativamente distintas.

Este trabalho visa analisar a composição físico-química e o perfil sensorial de cinco diferentes marcas de iogurte grego encontradas em comércio local, evidenciando a distinção existente entre elas, e também a aceitação das mesmas por meio de análise sensorial. Portanto, essa pesquisa pode contribuir como referência para o desenvolvimento de um Padrão de Identidade e Qualidade de iogurte grego no Brasil.

\section{MATERIAL E MÉTODOS}

O presente trabalho foi realizado no Instituto Federal de Ciências e Tecnologia do Sul de Minas Gerais - Campus Machado, situado a Rodovia Machado Paraguaçu, km 03 - Bairro Santo Antônio. Cinco marcas diferentes (A, B, C, D e E) de iogurte grego foram analisadas no laboratório de Bromatologia e de Análise Sensorial da referida instituição. Os iogurtes gregos integrais e naturais, obtidos de três lotes diferentes de cada uma das marcas, foram adquiridos nos supermercados do Sul de Minas Gerais, nas cidades de Machado, Poços de Caldas e Pouso Alegre, nos períodos de abril a junho de 2016.

\section{Análises físico químicas}

As análises físico-químicas foram realizadas em duplicata, referente a cada lote. São elas: sólidos totais e umidade por gravimetria (IAL, 2008); cinzas por gravimetria e incineração em mufla (IAL, 2008); gordura por butirômetro específico para iogurte (IAL, 2008); proteína pelo método de Kjeldahl (IAL, 2008); acidez em ácido lático por titulometria (IAL, 2008); pH por pH metro (IAL, 2008) e cor pelo colorímetro Minolta, método CIELAB.

\section{Análises Sensoriais}

Para a análise sensorial, foi colocada uma amostra de cada tratamento em copos descartáveis de $50 \mathrm{~mL}$ em quantidades padronizadas de 30 gramas a $5^{\circ} \mathrm{C}$ e codificadas com três dígitos aleatórios cada uma. As mesmas foram dispostas em bandejas de isopor, sob condições de cabines individuais, juntamente com um copo de água mineral a temperatura ambiente, para que os participantes neutralizem o sabor do paladar entre um tratamento e outro. Junto com as amostras, foi colocada a ficha de análise sensorial para que cada julgador expressasse a sua aceitação sobre os iogurtes.

As marcas foram avaliadas por meio do teste de aceitação sensorial para os atributos: aparência, aroma, sabor, consistência e avaliação geral. Para o teste, foi adotada a escala hedônica de 7 pontos, sendo 1 desgostei muitíssimo e 7 gostei muitíssimo. Também foi avaliada a intenção de compra do produto, onde o provador avaliou cada amostra em uma escala de cinco pontos, em que 5 representa que "certamente compraria" o produto e, 1 "certamente não compraria" o produto (IAL, 2008). O painel da análise sensorial foi de cem provadores não treinados e aleatórios, na faixa etária entre quinze e quarenta anos. 


\section{Análise Estatística}

Os dados obtidos foram distribuídos em delineamento em blocos casualizados e submetidos à análise estatística ANOVA, utilizando o teste de Tukey ao nível de significância de 5\% e as comparações foram para as cinco marcas analisadas e seus parâmetros. Foi utilizado o software Sisvar versão 5.6.

\section{RESULTADOS E DISCUSSÃO}

A Tabela 1 abaixo mostra os resultados encontrados nas análises físico químicas referentes aos sólidos totais, gordura, proteína, acidez, $\mathrm{pH}$ e Cor $\left(\mathrm{a}^{*}, \mathrm{~b}^{*}, \mathrm{~L}^{*}\right)$.

A amostra B apresentou o menor valor de sólidos totais $(15,53 \mathrm{~g} / 100 \mathrm{~g})$ dos iogurtes gregos analisados, enquanto que, o maior valor foi para a amostra D e amostra E, 27,54 e $28,20 \mathrm{~g} / 100 \mathrm{~g}$, respectivamente.

Foi observada uma grande diferença entre as porcentagens de sólidos totais nas amostras analisadas, o que reforça a neces- sidade do estabelecimento de critérios e padrões que definam o mínimo aceitável a este produto. A média encontrada entre as amostras analisadas foi de $23,89 \mathrm{~g} / 100 \mathrm{~g}$, sendo esta a sugestão para o desenvolvimento de um futuro padrão de identidade e qualidade específico para iogurte grego. Atamian et al. (2014) encontrou o valor médio de $26,13 \mathrm{~g} / 100 \mathrm{~g}$ para sólidos totais em iogurte grego integral natural de leite bovino. Desai et al. (2013) analisou quinze marcas do mercado norte americano e encontrou valores entre 15,00 e 23,80 g/100g para sólidos totais, demonstrando que a falta de uma regulamentação específica para este produto pode gerar variações como as encontradas neste trabalho.

Para gordura, os maiores valores foram encontrados na amostra E $(6,30 \mathrm{~g} / 100 \mathrm{~g})$, e o menor valor na amostra B (3,90 g/100g). De acordo com a Instrução Normativa $n^{\circ} 46$ (BRASIL, 2007), os iogurtes são classificados em: com creme (matéria gorda mínima de $6 \mathrm{~g} / 100 \mathrm{~g}$ ); integral (matéria gorda mínima de $3 \mathrm{~g} / 100 \mathrm{~g})$; parcialmente desnatado

Tabela 1 - Análises físico químicas dos iogurtes gregos integrais naturais

\begin{tabular}{cccccc}
\hline Análise & A & B & C & D & E \\
\hline Sólidos totais $(\mathrm{g} / 100 \mathrm{~g})$ & $25,14^{\mathrm{b}}$ & $15,53^{\mathrm{c}}$ & $23,03^{\mathrm{b}}$ & $27,54^{\mathrm{a}}$ & $28,20^{\mathrm{a}}$ \\
\hline Gordura $(\mathrm{g} / 100 \mathrm{~g})$ & $4,55^{\mathrm{c}}$ & $3,90^{\mathrm{d}}$ & $4,90^{\mathrm{bc}}$ & $5,15^{\mathrm{b}}$ & $6,30^{\mathrm{a}}$ \\
\hline Proteína $(\mathrm{g} / 100 \mathrm{~g})$ & $8,17^{\mathrm{a}}$ & $3,21^{\mathrm{d}}$ & $5,25^{\mathrm{bc}}$ & $6,67^{\mathrm{c}}$ & $6,42^{\mathrm{b}}$ \\
\hline Acidez $(\mathrm{g}$ de Ácido Lático/ 100g) & $1,24^{\mathrm{b}}$ & $1,37^{\mathrm{a}}$ & $1,03^{\mathrm{c}}$ & $1,22^{\mathrm{b}}$ & $1,07^{\mathrm{c}}$ \\
\hline $\mathrm{pH}$ & $4,26^{\mathrm{a}}$ & $4,36^{\mathrm{a}}$ & $4,34^{\mathrm{a}}$ & $4,40^{\mathrm{a}}$ & $4,26^{\mathrm{a}}$ \\
\hline $\mathrm{L}$ & $77,67^{\mathrm{a}}$ & $71,41^{\mathrm{b}}$ & $77,88^{\mathrm{a}}$ & $77,94^{\mathrm{a}}$ & $78,11^{\mathrm{a}}$ \\
\hline $\mathrm{a}^{*}$ & $-2,76^{\mathrm{c}}$ & $-1,81^{\mathrm{a}}$ & $-2,32^{\mathrm{bc}}$ & $-2,43^{\mathrm{bc}}$ & $-2,25^{\mathrm{ab}}$ \\
\hline $\mathrm{b}^{*}$ & $7,55^{\mathrm{a}}$ & $7,41^{\mathrm{a}}$ & $7,86^{\mathrm{a}}$ & $8,52^{\mathrm{a}}$ & $8,32^{\mathrm{a}}$ \\
\hline
\end{tabular}

a,b Média seguidas de letras iguais nas linhas não diferem estatisticamente ao nível de significância de 5\% pelo teste de Tuckey.

A, B, C, D e E: marcas de iogurtes gregos adquiridas em comércio local.

L: luminosidade (valores positivos de L indicam coloração mais clara e valores negativos mais escura); a*:coordenada vermelho/verde (valores positivos de a* “+ a" indicam coloração vermelha e valores negativos

"- a" verde); b*: coordenada amarelo / azul (valores positivos de b* " + b" indicam amarelo e valores negativos

"- b" azul) 
(matéria gorda máxima de $2,9 \mathrm{~g} / 100 \mathrm{~g}$ ); desnatado (matéria gorda máxima de $0,5 \mathrm{~g} / 100 \mathrm{~g}$ ). $\mathrm{Na}$ falta de legislação específica para iogurte grego, e utilizando a IN $n^{\circ} 46$, a amostra E apresentou características similares ao "iogurte com creme", mesmo não sendo comum a adição de creme neste produto e sim a concentração dos sólidos totais. As demais amostras foram classificadas como iogurte integral.

Devido à grande preocupação atual dos consumidores em relação ao teor de gordura nos alimentos, esta grande discrepância entre os valores de gordura encontrados no mesmo tipo de produto, gera uma dificuldade para a população no consumo diário de matéria gorda, podendo gerar um equívoco na escolha de qual marca levar na hora da compra do produto.

Sömer et al. (2012), analisou diferentes iogurtes gregos comercializados na Turquia, encontrando valores para gordura entre 5,51 e 11,61 g/100g. Silva et al. (2014) desenvolveu iogurte grego com adição de polpa de pequi e, os valores de gordura encontrados foram entre 5,89 e 6,44 g/100g.

De acordo Ramos et al. (2009), o teor de gordura influencia na textura do iogurte grego, contribuindo para maiores valores dos parâmetros gomosidade, firmeza e adesividade, influenciando na percepção sensorial deste atributo.

A maioria dos compostos que influenciam o flavor do iogurte grego são produzidos pela lipólise da gordura presente no leite. Estes componentes do flavor estão correlacionados com as propriedades sensoriais de aroma e sabor. O teor de gordura, neste caso, passa a ter um papel relevante na avaliação destes atributos sensoriais (CHENG, 2010).

A média dos valores de gordura encontrados neste trabalho foi de 4,96 g/100g, sendo esta a sugestão para o desenvolvimenmento de um futuro padrão de identidade e qualidade específico para iogurte grego.
Para a análise de proteína dos iogurtes gregos analisados, o maior valor foi encontrado na amostra $\mathrm{A}(8,17 \mathrm{~g} / 100 \mathrm{~g})$, e o menor valor foi encontrado na amostra B $(3,21 \mathrm{~g} / 100 \mathrm{~g})$. De acordo com a Instrução Normativa $n^{\circ} 46$ (BRASIL, 2007), o mínimo de proteína láctea para iogurte é de $2,9 \mathrm{~g} / 100 \mathrm{~g}$, estando todas as amostras analisadas dentro da regulamentação para iogurte tradicional. A média das amostras analisadas foi $5,94 \mathrm{~g} / 100 \mathrm{~g}$ para proteína, sendo esta a sugestão deste trabalho para o desenvolvimento de um futuro padrão de identidade e qualidade específico para iogurte grego.

Desai et al. (2013), analisou quinze marcas de iogurte grego comercializados no mercado norte americano, e foram encontrados valores entre 5,8 e 10,6 g/100g para proteína. Para Atamian et al. (2014) foi encontrado o valor médio de $9,18 \mathrm{~g} / 100 \mathrm{~g}$ para proteína em iogurte grego integral natural de leite bovino.

De acordo com Sodini et al. (2010), o teor de proteína influencia fortemente na textura do iogurte, principalmente na formação e firmeza do gel. Este fator afeta a microestrutura e a reologia do produto, impactando na percepção sensorial do consumidor.

Webb (2014) concluiu que o iogurte é uma excelente fonte de proteína de alta qualidade, promovendo saciedade, ajudando na manutenção da saúde e do peso corporal e auxiliando no crescimento muscular e ósseo.

De acordo com Douglas et al. (2013), o consumo de iogurte grego com alto teor de proteína pela manhã levou a uma redução da fome, aumento da saciedade e maior distanciamento da refeição subsequente, quando comparado ao iogurte grego com teor de proteína mais baixo.

Em contrapartida, o consumo de iogurte grego precisa ser avaliado cuidadosamente em dietas de pessoas que sofrem diálise, devido ao seu alto teor de proteína e a falta de padrão de qualidade e identidade deste produto (STALL, 2012). 
$\mathrm{Na}$ análise de acidez em ácido lático, o maior valor foi encontrado na amostra $\mathrm{B}(1,37$ $\mathrm{g}$ de ácido lático/100g) e, os menores valores foram encontrados nas amostras C e E $(1,03$ e 1,07 g de ácido lático/100g, respectivamente). De acordo com a Instrução Normativa $n^{\circ} 46$ (BRASIL, 2007), a acidez em g de ácido lático/100g para iogurte deve apresentar-se entre 0,6 e 1,5; estando todas as amostras deste trabalho dentro da regulamentação.

Ott et al. (2000) analisou sensorialmente com um painel de avaliadores treinados, a influência da acidez nas propriedades sensoriais do iogurte. Vários atributos descritivos variaram linearmente, demonstrando uma grande sensibilidade de acordo com o seu aumento. Discrepâncias significativas de flavor foram encontradas devido à diferença de acidez na concentração de três compostos fundamentais no aroma do produto, acetaldeído, 2,3-butanediona e 2,3-pentanediona, enfatizando a importância desta característica no flavor do iogurte.

Os resultados encontrados para a acidez neste trabalho são similares aos encontrados na literatura. Serafeimidou et al. (2012), desenvolveu iogurtes gregos utilizando leite bovino em diferentes regiões da Grécia, e encontrou-se acidez entre 0,92 e 1,39 g de ácido lático/100g. Atamian et al. (2014) encontraram valor médio para acidez de 1,12 g em ácido lático/100g em iogurte grego integral de leite bovino.

Referente ao $\mathrm{pH}$, não houve diferença significativa entre as amostras, apesar de ter sido detectado entre os valores de acidez, esse fator não refletiu para o $\mathrm{pH}$. De acordo com Tamime (2006), isso ocorre devido à diferença analítica destes dois ensaios. A determinação de acidez no iogurte quantifica o ácido lático (g ácido lático/100g). Já o pH, quantifica o logaritmo de hidrogênio $(\mathrm{H}+)$, que sofre alterações devido alguns aminoácidos presentes no iogurte, o que não é quantificado na acidez, explicando, portanto, esse fator.

Os valores encontrados para a variável L* permitem concluir que a amostra $B$ obteve um valor significativamente inferior as demais $(71,41)$. Este resultado mostra uma menor luminosidade para esta amostra, podendo representar uma influência na análise sensorial de cor para iogurte grego integral natural, onde, geralmente, a cor branca é predominante e mais apreciada.

Silva et al. (2014) desenvolveu iogurte grego integral natural de leite bovino, encontrando valores médios de $L^{*}$ de 83,72 ; superiores ao encontrados neste trabalho.

A Tabela 2 abaixo apresenta os resultados da análise sensorial dos iogurtes gregos integrais naturais analisados para os

Tabela 2 - Análise sensorial dos iogurtes gregos integrais naturais analisados para os atributos aparência, aroma, sabor, consistência e avaliação geral

\begin{tabular}{cccccc}
\hline Atributo Sensorial & A & B & C & D & E \\
\hline Aparência & $5,90^{\mathrm{a}}$ & $3,59^{\mathrm{d}}$ & $5,22^{\mathrm{b}}$ & $5,38^{\mathrm{bc}}$ & $4,69^{\mathrm{c}}$ \\
\hline Aroma & $5,68^{\mathrm{a}}$ & $4,87^{\mathrm{c}}$ & $5,50^{\mathrm{ab}}$ & $5,14^{\mathrm{abc}}$ & $4,99^{\mathrm{bc}}$ \\
\hline Sabor & $6,16^{\mathrm{a}}$ & $4,42^{\mathrm{d}}$ & $5,47^{\mathrm{b}}$ & $4,81^{\mathrm{bc}}$ & $4,77^{\mathrm{c}}$ \\
\hline Consistência & $5,79^{\mathrm{a}}$ & $3,60^{\mathrm{d}}$ & $5,60^{\mathrm{b}}$ & $5,12^{\mathrm{bc}}$ & $4,77^{\mathrm{cd}}$ \\
\hline Avaliação Geral & $5,76^{\mathrm{a}}$ & $4,70^{\mathrm{c}}$ & $5,65^{\mathrm{ab}}$ & $5,02^{\mathrm{c}}$ & $5,14^{\mathrm{b}}$ \\
\hline
\end{tabular}

a,b Média seguidas de letras iguais nas linhas não diferem estatisticamente ao nível de significância de 5\% pelo teste de Tuckey. 
atributos aparência, aroma, sabor, consistência e avaliação geral.

Para aparência, a maior média de nota foi encontrada na amostra A $(5,9)$, e a menor foi na B $(3,59)$. Esta por sua vez, obteve menores valores de $L^{*}(71,41)$ e para o atributo sensorial aparência $(3,59)$. Essa tendência pode ser explicada pelo fato do iogurte grego integral natural ser, mais apreciado quando apresenta cor branca, a qual é altamente influenciada pelo valor de $\mathrm{L}^{*}$.

Nos resultados do atributo sensorial aroma dos iogurtes gregos integrais analisados, as médias de notas encontradas não apresentaram resultados conclusivos.

$\mathrm{O}$ atributo sabor é influenciado pelo teor de gordura, acidez e sólidos totais. A amostra B obteve a menor média de nota para sabor $(4,42)$ e, simultaneamente o menor valor de gordura $(3,90 \mathrm{~g} / 100 \mathrm{~g})$, maior valor de acidez (1,37 g de ácido lático/100g) e menor valor para sólidos totais $(15,53 \mathrm{~g} / 100 \mathrm{~g})$.

A marca A, que obteve melhor aceitação para sabor, apresentou valores intermediários para gordura $(4,55 \mathrm{~g} / 100 \mathrm{~g})$, acidez (1,24 g de ácido lático/100g) e sólidos totais $(25,14 \mathrm{~g} / 100 \mathrm{~g})$.
Nos resultados do atributo consistência dos iogurtes gregos integrais analisados, a maior média de nota foi obtida para a amostra A $(5,79)$ e a menor para as amostras B $(3,6)$ e E $(4,77)$. A característica de consistência é influenciada pelo teor de proteína. A amostra A apresentou o maior valor de proteína $(8,17$ $\mathrm{g} / 100 \mathrm{~g}$ ) assim como a maior média da nota para consistência.

Para o atributo sensorial "avaliação geral", as menores médias de notas foram encontradas nas amostras B $(4,70)$ e D $(5,02)$. A menor média de nota para a amostra $B$ foi coerente, já que recebeu também a menor média de nota para aparência e sabor.

A Figura 1 abaixo apresenta os valores encontrados no teste afetivo por intenção de compra.

As diferenças físico-químicas e sensoriais refletiram nos resultados, onde a marca A apresentou a maior porcentagem $(81 \%)$ para os provadores que certamente comprariam o produto, e menor porcentagem para os que certamente não o comprariam (1\%). Já a marca $\mathrm{B}$, apresentou a maior porcentagem para certamente não comprariam o produto (35\%) e menor para certamente comprariam o produto $(4 \%)$.

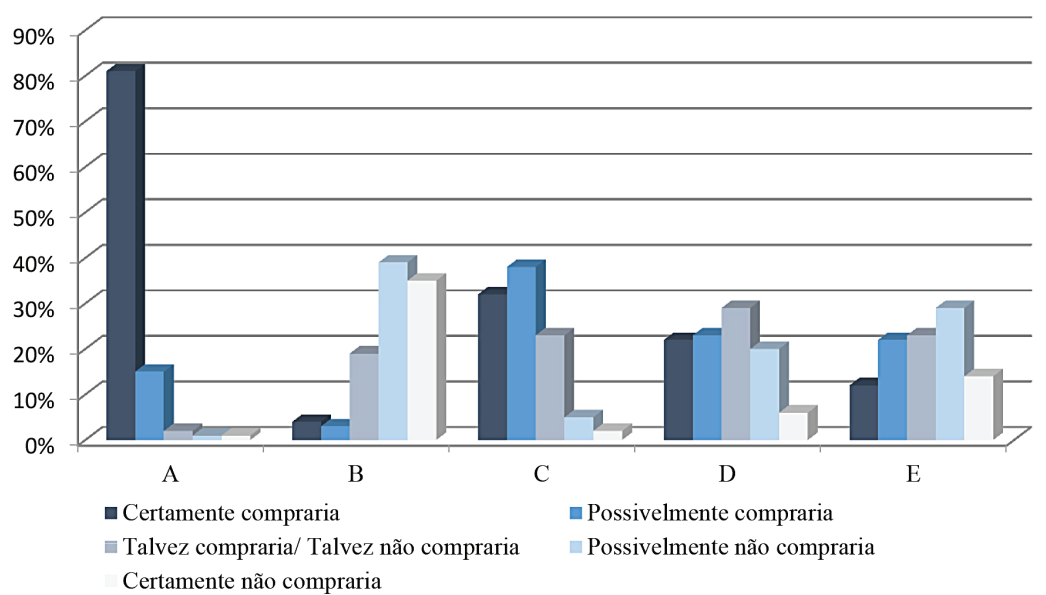

Figura 1 - Teste de intenção de compra (\%) dos iogurtes gregos integrais naturais 
A partir deste cenário é possível traçar um perfil do consumidor de iogurtes gregos. Um produto com baixo teor de sólidos totais, gordura, proteína e mais ácido, pode possuir maior rejeição à aquisição do produto (marca B). Em contrapartida, também houve uma objeção (14\%) pela amostra (marca E) com relação ao teor de gordura mais elevado. A amostra A obteve os melhores resultados para a intenção de compra, ficando claro que um teor mediano de gordura, sólidos totais e acidez, e um teor mais elevado de proteína, se enquadram de maneira mais adequada no perfil de intenção de compra do produto estudado neste trabalho.

\section{CONCLUSÕES}

As distintas composições químicas das marcas analisadas acarretam em diferenças sensoriais e na aceitação das mesmas. Os resultados indicam que uma amostra com valores intermediários de sólidos totais, gordura, acidez e maior teor de proteína se enquadram de maneira mais adequada no perfil de intenção de compra do produto estudado neste trabalho.

Todas as marcas de iogurtes gregos analisadas se adequam à legislação vigente Instrução Normativa $n^{\circ} 46$. Em contrapartida, comprova-se que existe uma grande discrepância na composição química entre as amostras, portanto, se faz necessário a criação de um Padrão de Identidade e Qualidade para iogurte grego no Brasil. Os dados apresentados nos resultados deste trabalho podem colaborar para o desenvolvimento desta nova legislação.

\section{REFERÊNCIAS}

ATAMIAN, S. et al. The characterization of the physicochemical and sensory properties of full-fat, reduced-fat and low-fat bovine, caprine, and ovine Greek yogurt (Labneh).
Food science \& nutrition, v. 2, n. 2, p. 164173, 2014.

BRASIL, Ministério da Agriculta, Pecuária e Abastecimento. Instrução Normativa $n^{\circ}$ 46, de 23 de outubro de 2007. Regulamento Técnico de Identidade e Qualidade de Leites Fermentados. Diário Oficial da República Federativa do Brasil, Brasília, 24 out. 2007. Seção 1, p. 4.

CHENG, H. Volatile flavor compounds in yogurt: a review. Critical reviews in food science and nutrition, v. 50, n. 10, p. 938950, 2010.

COSTA, M. F. et al. Desenvolvimento e caracterização de iogurte grego simbiótico sabor baunilha. In: SEMANA DA QUÍMICA, 35.; Jornada da Pós-Graduação em Alimentos, 8., 2014, Rio de Janeiro. Anais... Rio de Janeiro: Instituto Federal de Educação, Ciência e Tecnologia do Rio de Janeiro, 2014.

DESAI, N. T.; SHEPARD, L.; DRAKE, M. A. Sensory properties and drivers of liking for Greek yogurts. Journal of dairy science, v. 96, n. 12, p. 7454-7466, 2013.

DOUGLAS, S. M. et al. Low, moderate, or high protein yogurt snacks on appetite control and subsequent eating in healthy women. Appetite, v. 60, p. 117-122, 2013.

FERREIRA, G. S. Iogurte grego do Brasil, só mesmo no Brasil. Estadão, São Paulo, 18 de fevereiro de 2014, Economia \& Negócios. Disponível em: <http://economia.estadao. com.br/noticias/geral,iogurte-grego-dobrasil-so-mesmo-no-brasil,177996e>. Acesso em: 09 mar. 2017.

LANGSDORFF, J. Gregos tiram iogurtes da mesmice. Jornal Meio \& Mensagem, 10 de setembro de 2012. Disponível em: <http:// 
www.foodandnews.com/2772-gregos-tiramiogurte-da-mesmice>. Acesso em: 09 mar. 2017.

INStituto ADOLfo LUTZ. Métodos físico-químicos para análise de alimentos, $4^{\mathrm{a}}$ ed., 1 ed. digital. São Paulo: Instituto Adolfo Lutz, 2008. 1020 p.

OTT, A. et al. Sensory investigation of yogurt flavor perception: Mutual influence of volatiles and acidity. Journal of Agricultural and Food chemistry, v. 48, n. 2, p. 441-450, 2000.

RAMOS, T. de M. et al. Perfil de textura de Labneh (iogurte Grego). Revista Instituto de Laticínios Cândido Tostes, v. 64, n. 369, p. 8-12, 2009.

SERAFEIMIDOU, A. et al. Chemical characteristics, fatty acid composition and conjugated linoleic acid (CLA) content of traditional Greek yogurts. Food chemistry, v. 134, n. 4, p. 1839-1846, 2012.

SILVA, B. S. et al. Sensory, physicochemical and microbiological characteristics of Greek style yogurt flavored with pequi (Caryocar Brasiliense, Cambess). African Journal of Biotechnology, v. 13, n. 37, p. 3797-3804, 2014.

SODINI, I. et al. The relative effect of milk base, starter, and process on yogurt texture: a review. Critical reviews in food science and nutrition, v. 44, n. 2, p. 113137, 2004.

SÖMER, V. F.; KILIÇ, G. B. Microbiological, physicochemical properties and biogenic amine contents of the strained yoghurts from Turkish local markets. African Journal of Biotechnology, v. 11, n. 78, p. 1433814343, 2012.

STALL, S. Considering Greek yogurt for chronic kidney disease. Journal of Renal Nutrition, v. 22, n. 6, p. e 57-e62, 2012.

TAMIME, A. Y. Fermented milks. Oxford: Blackwell Science, 2006. 266 p.

WEBB, D.; DONOVAN, S. M.; MEYDANI, $\mathrm{S}$. N. The role of yogurt in improving the quality of the American diet and meeting dietary guidelines. Nutrition reviews, v. 72, n. 3, p. 180-189, 2014. 